\title{
Dyke-Davidoff-Masson Syndrome with crossed cerebellar atrophy
}

\author{
Rohit Kumar $D N B^{1}$ iD, Deepak Kumar $M D^{2}$ iD, Himanshu Mishra $D N B^{3}$ iD, \\ Sanjay Kumar Suman $M D^{4}$ iD, Umakant Prasad $M D^{5}$ iD \\ 1,2,3,4,5 Department of Radio-diagnosis, Indira Gandhi Institute of Medical Science, Patna, India
}

Date of submission: $17^{\text {th }}$ May 2021

Date of acceptance: $16^{\text {th }}$ August 2021

Date of publication: $1^{\text {st }}$ September 2021

\begin{abstract}
Dyke-Davidoff-Masson Syndrome (DDMS) is a rare neurological condition characterised clinically by recurrent seizures, facial asymmetry, hemiplegia and mental retardation likely due to foetal or early childhood cerebral insult. We describe the MRI findings of DDMS in a 10-year-old male child. MRI brain revealed right cerebral atrophy, ipsilateral thickening of calvarium, right lateral ventricular dilatation, hyper-pneumatisation of frontal sinus, and contralateral cerebellar atrophy which are consistent with DDMS.
\end{abstract}

Key words: Cerebellar atrophy, Dyke-Davidoff-Masson syndrome, MRI.

\section{Introduction}

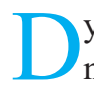
yke-Davidoff-Masson syndrome presents during the neonatal, infantile, or early childhood period and is diagnosed by various clinical as well as radiological findings. ${ }^{1}$ Clinical features result likely due to cerebral insult in utero or traumatic brain damage in early life and include intractable seizures, facial asymmetry, contralateral hemiparesis or hemiplegia, mental retardation, developmental delay in the form of learning difficulties, speech and language disorders. ${ }^{2,3}$ Radiological manifestations include cerebral hemiatrophy, homolateral hypertrophy of calvarium and sinuses, and contralateral cerebellar hemiatrophy. ${ }^{4,5,6}$ Many a times, it may be misdiagnosed by majority of clinicians or radiologists. Our patient, who was initially misdiagnosed as a case of Rasmussen encephalitis, was later diagnosed as a case of DDMS on the basis of imaging findings.

Access this article online
Website: https://www.nepjol.info/index.php/NJN
DOI: https://doi.org/10.3126/njn.v18i3.37163
HOW TO CITE
Kumar R, Kumar D, Mishra H, Suman SK, Prasad U. Dyke-
Davidoff-Masson Syndrome with crossed cerebellar atrophy.
NJNS. 2021;18(3):73-5.

Address for correspondence:

Dr. Deepak Kumar

Associate Professor, Department of Radio-diagnosis, Indira Gandhi Institute of Medical Science,

Sheikhpura, Patna, Bihar, India.

E-mail: 1999deepak@gmail.com

Phone: +919835284456

Copyright (C) 2021 Nepalese Society of Neurosurgeons (NESON)

ISSN: 1813-1948 (Print), 1813-1956 (Online)

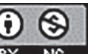

This work is licensed under a Creative Commons Attribution-Non Commercial 4.0 International License.

\section{Case Report}

A 10-year-old male child presented with multiple episodes of intractable seizures and left hemiparesis for the last 5-6 months. Birth was at term and uneventful. There was no noticeable history of trauma after birth. On examination, he had microcephaly without facial asymmetry. Neurological examinations revealed reduced power in left upper and lower limbs (4/5) with brisk tendon reflexes. Vision and hearing were normal, cranial nerves were intact, but there were difficulties in speech. Systemic examinations including vitals were normal.

Complete blood picture revealed mild anaemia, but it was otherwise within normal limits. Liver and renal function tests were normal. NCCT brain done previously, reported right cerebral atrophy with prominence of cortical sulci and cisterns, dilatation of ipsilateral lateral ventricle indicative of features of Rasmussen encephalitis. Subsequent MRI brain performed at our centre showed right cerebral atrophy with features of volume loss in the form of widened cortical sulci, prominent cisterns, and ex-vacuo dilatation of right lateral ventricle associated with mild ipsilateral falcine displacement and ipsilateral calvarial thickening. Contralateral cerebellar atrophy was also noted.

\section{Discussion}

DDMS or cerebral hemiatrophy was first described by Dyke, Davidoff, and Masson in 1933 on the basis of skull radiographic findings in 9 patients who clinically presented with seizures, hemiparesis, facial asymmetry, mental retardation. ${ }^{7}$ They found calvarial thickening and hyperpneumatization of sinuses in the same side of the lesion. Finally, they concluded that these changes occur in brain/skull secondary to cerebral insults in the form of congenital abnormalities, vascular malformations, 


\section{Kumar et al}
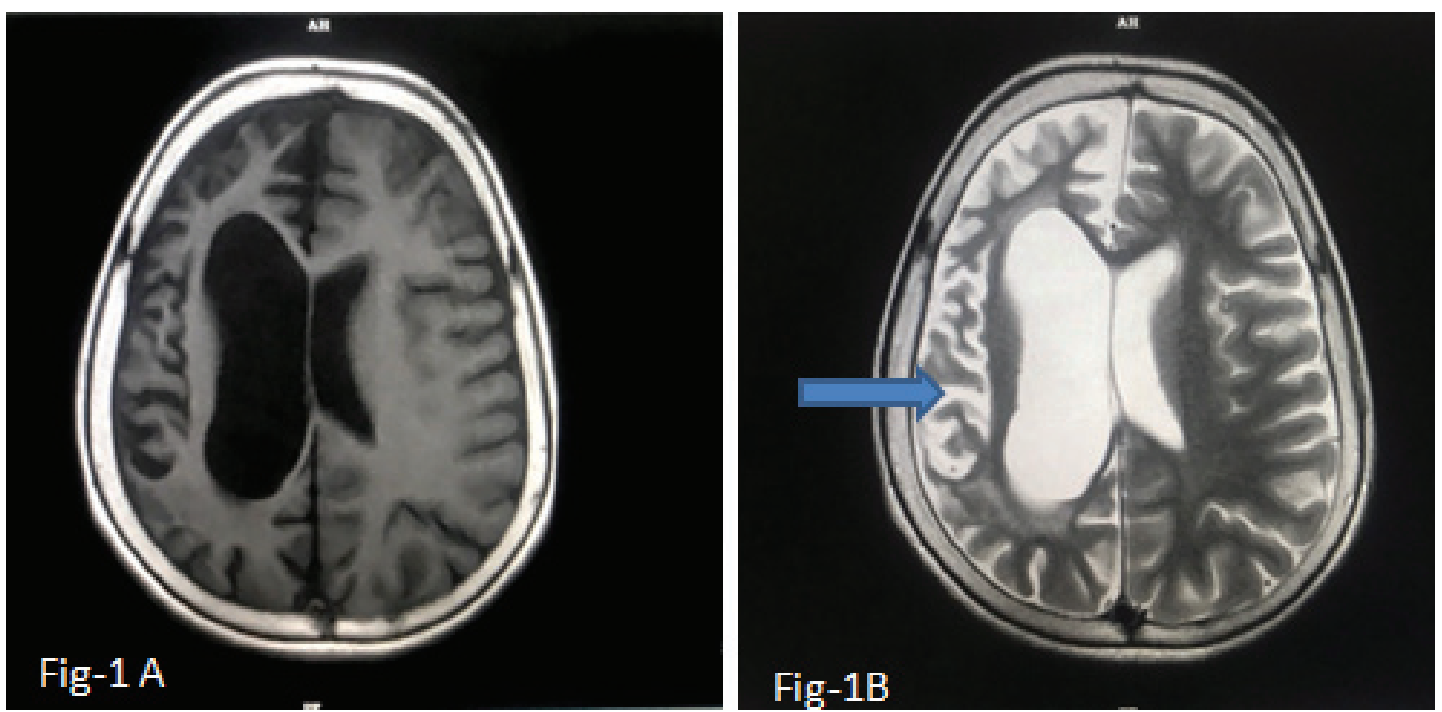

Figure 1a, 1b: (T1W) and (T2W) axial images show right cerebral atrophy with features of volume loss in the form of widened cortical sulci, cisterns and ex-vacuo dilatation of right ventricle associated with mild ipsilateral calvarial thickening.

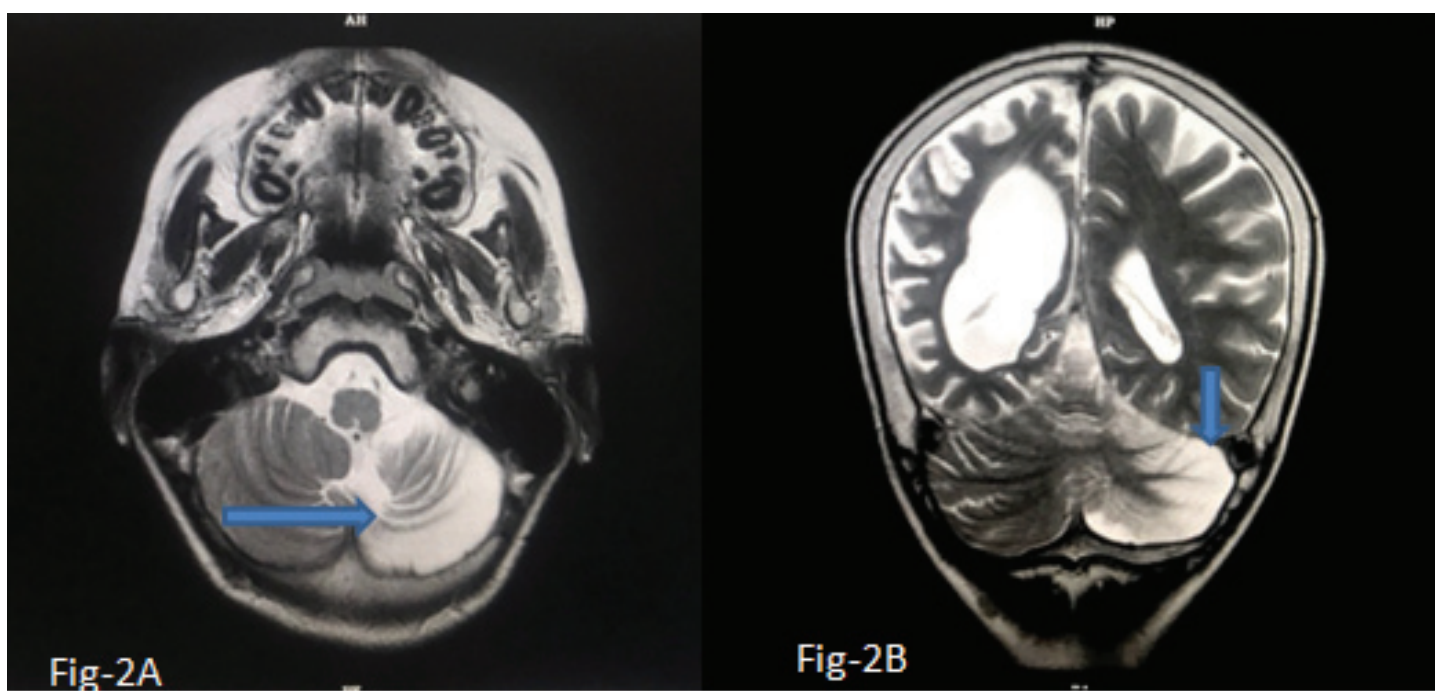

Figure 2a, 2b: T2WI axial and T2WI coronal images show left cerebellar atrophy.

and vascular occlusions leading to cerebral infarction and infections in the prenatal period, birth trauma in the perinatal period as well as infection, tumour, trauma, hypoxia, haemorrhage in the postnatal period.

Cross sectional imaging reveals elevation of orbital roof, sphenoid wing, and petrous ridge ipsilateral to the lesion as skull manifestations as well as cerebral hemiatrophy, prominent cortical sulci and cisterns, exvacuo dilatation of ipsilateral ventricular system, and pachygyria as brain parenchymal changes. In addition to these findings, contralateral cerebellar atrophy is also occasionally seen in DDMS which was present in our case and is infrequently reported in literature. ${ }^{8}$

Development of the nervous system starts at 3 weeks of gestation and $3 / 4$ th of adult size is reached by the age of
3 years. Cerebral insults in the perinatal period hampers the normal development of brain which is compensated by secondary changes in the form of increased width of diploic spaces, i.e., calvarial thickening, ipsilateral hyperaeration of frontal, ethmoid, and mastoid air cells, and elevation of orbital roof. ${ }^{9}$ These changes begin to manifest when cerebral insults occur before the age of 3 years and may become evident as early as 9 months after the cerebral injury. ${ }^{10}$ Vascular occlusion involving the middle cerebral artery and decrease in carotid artery flow due to coarctation of aorta are the main vascular causes of DDMS. ${ }^{11}$ Our patient had a history of prolonged febrile seizures at the age of 3 years and was treated as a case of encephalitis. He came to our department at the age of 10 years with the complaints of intractable seizures for 5 


\section{Dyke-Davidoff-Masson syndrome}

months. MRI findings comprised of right cerebral atrophy with features of volume loss in the form of widened cortical sulci, prominent cisterns, and ex-vacuo dilatation of right lateral ventricle associated with mild ipsilateral calvarial thickening and mild ipsilateral falcine displacement in addition to contralateral cerebellar atrophy.

Differential diagnosis for cerebral hemiatrophy includes Rasmussen encephalitis, hemimegalencephaly, and Sturge Weber syndrome. Rasmussen encephalitis is characterised by focal lobar or cerebral hemispheric atrophy (volume loss) without calvarial thickening. ${ }^{12}$ Sturge Weber syndrome is characterised by leptomeningeal angiomatosis, cerebral venous malformation, intracranial tram track calcification, and cortical laminar necrosis. ${ }^{13}$ Hemimegalenncephaly is characterised by enlarged dysplastic unilateral cerebral hemisphere or a portion of hemisphere, so that contralateral normal cerebral hemisphere may be mistaken for atrophy. Enlarged ipsilateral lateral ventricle, thickened calvarial vault, and contralateral displacement of the posterior falx are also noted in hemimegalencephaly. ${ }^{14}$ Treatment of DDMS depends on symptoms; it includes anticonvulsant therapy, physiotherapy, occupational therapy, and speech therapy. Surgery in the form of hemispherectomy can be performed for intractable seizures with approximately $85 \%$ success rate. ${ }^{15}$ Prognosis is better if the onset of hemiparesis occurs after the age of 2 years without intractable seizures. ${ }^{16}$

\section{Conclusion}

Dyke-Davidoff-Masson syndrome is a rare cause of cerebral hemiatrophy in children and may sometimes be misdiagnosed. Apart from clinical presentations and risk factors, imaging findings play an important role in making accurate diagnosis as well as help to decide appropriate management of patients for the clinicians.

Acknowledgement: The authors would like to thank the patient, his family, and the Departments of Pediatrics and Radiology of our institute.

\section{Conflict of Interest: None \\ Source(s) of support: None}

\section{References}

1. Sharma S, Goyal D, Negi A, Sood RG, Jhobta A, Surya M. Dyke-Davidoff-Masson syndrome. Indian J Radiol Imaging. 2006;16:165-6. https://doi. org/10.4103/0971-3026.29077

2. Goyal J, Shah V, Rao S, Jindal N. Dyke-DavidoffMasson syndrome in children. J Pediatr Neonatal. 2009;10:101-7. https://doi.org/10.5580/10ad
3. Ono K, Komai K, Ikeda T. Dyke-Davidoff-Masson syndrome manifested by seizure in late childhood: A case report. J Clin Neurosci. 2003;10:367-71. https:// doi.org/10.1016/S0967-5868(03)00011-0

4. Shetty DS, Lakhkar BN, Jhon JR. Dyke-DavidoffMasson syndrome. Neurol India. 2003;51:136.

5. Koshy B, Surendrababu NR. Dyke-Davidoff-Masson syndrome. Ann Acad Med Singapore. 2010;39:5012 .

6. Behera MR, Patnaik S, Mohanty AK. DykeDavidoff-Masson syndrome. J Neurosci Rural Pract. 2012;3:411-3. https://doi.org/10.4103/09763147.102646

7. Dyke CG, Davidoff LM, Masson CB. Cerebral hemiatrophy and homolateral hypertrophy of the skull and sinuses. Surg Gynecol Obstet. 1933;57:588-600.

8. Winkler DT, Probst A, Wegmann W, Tolnay M. DykeDavidoff-Masson syndrome with crossed cerebellar atrophy: An old disease in a new millennium. Neuropathol Appl Neurobiol. 2001;27:403-5. https:// doi.org/10.1046/j.0305-1846.2001.00340.x

9. Singh P, Saggar K, Ahluwalia A. Dyke-DavidoffMasson syndrome: Classical imaging findings. J Pediatr Neurosci. 2010;5:124-5. https://doi. org/10.4103/1817-1745.76108

10. Solomon GE, Hilal SK, Gold AP, Carter S: Natural history of acute hemiplegia of childhood. Brain. 1970;93:107-20. https://doi.org/10.1093/ brain/93.1.107

11. Teal JS, Rumbaugh CL, Bergeron RT, Segalim HD. Congenital absence of internal carotid artery associated with cerebral hemiatrophy, absence of the external carotid artery. AJR. 1973;18:534-45. https:// doi.org/10.2214/ajr.118.3.534

12. Sheybani L, Schaller K, Seeck M. Rasmussen encephalitis: An update. Schweiz Arch Neurol Psychiatr. 2011;162:225-31. https://doi.org/10.4414/ sanp.2011.02298

13. Lo W, Marchuk DA, Ball KL, Juhász C, Jordan LC, Ewen JB, et al. Updates and future horizons on the understanding, diagnosis, and treatment of SturgeWeber syndrome brain involvement. Dev Med Child Neurol. 2012;54:214-23. https://doi.org/10.1111/ j.1469-8749.2011.04169.x

14. Abdel Razek AA, Kandell AY, Elsorogy LG, Elmongy A, Bassett AA. Disorders of cortical formation: MR imaging features. AJNR Am J Neuroradiol. 2009;30:4-11. https://doi.org/10.3174/ajnr.A1223

15. Narain NP, Kumar R, Narain B. Dyke-DavidoffMasson syndrome. Indian Pediatr. 2008;45:927-8.

16. Pendse NA, Bapna P, Menghani V, Diwan A. DykeDavidoff-Masson syndrome. Indian J Pediatr. 2004;71:943. https://doi.org/10.1007/BF02830843 